\title{
European League Against Rheumatism Classification Criteria for Juvenile Chronic Arthritis
}

National Cancer Institute

\section{Source}

National Cancer Institute. European League Against Rheumatism Classification Criteria

for Juvenile Chronic Arthritis. NCI Thesaurus. Code C121339.

A set of antiquated criteria used to assign children with chronic arthritis to one of six

mutually exclusive categories. 